JURNAL TERKNOSAINS

VOLUME 2

No. 2, 22 Juni 2013

Halaman 71-158

\title{
PENGEMBANGAN MATERIAL PASAK ENDODONTIK Ti/40HA DENGAN MENGGUNAKAN KONSEP FUNCTIONALLY GRADIENT MATERIAL
}

\author{
M.K. Herliansyah \\ Jurusan Teknik Mesin dan Industri Fakultas Teknik Universitas Gadjah Mada \\ Email:mkherliansyah@gmail.com \\ Margareta Rinastiti \\ Bagian Konservasi Gigi Fakultas Kedokteran Gigi Universitas Gadjah Mada \\ Isom Hilmi \\ Minat Studi Rekayasa Biomedis \\ Program Studi Bioteknologi Sekolah Pascasarjana Universitas Gadjah Mada
}

\begin{abstract}
Commercial endodontic pegs have a homogeneous composition and strength so that the transmission voltage of pegs to dentin often result in damage to the tooth root. The concept of functionally gradient material (FGM) is expected to overcome these problems by adjusting the mechanical properties of each peg to the nature of the teeth. This study aims to develop a material stake with the concept of FGM from Ti/40HA material that is composed of five layers with concentrations of HA from $0 \%-40 \%$ wt through the process of uni-axial pressing followed by sintering at $1200^{\circ} \mathrm{C}$ and $1400^{\circ} \mathrm{C}$ in argon gas. Then performed on each layer characterization by SEM/EDX, the optimum sintering temperature was determined by test- $t(p$ $<0,05)$. Morphological Testing showed that the composite of Ti/40HA still porous, while EDX shows the composition of Ca and $P$ increase as an indication of increment in the concentration of $H A$ as the decrement in concentration of the layer-1 (100\% Ti) up to layer-5 (60\% Ti-40\% HA). In conclusion, Ti/40HA200 and Ti/40HA200 composite materials can be produced by decreasing its roughness as the rising concentrations of HA in each section.
\end{abstract}

Keywords: functionally gradient material, Titanium, Hidroksiapatit, Hardness.

\begin{abstract}
ABSTRAK
Pasak endodontik komersial mempunyai komposisi dan kekuatan yang homogen sehingga transmisi tegangan dari pasak ke dentin sering mengakibatkan kerusakan akar gigi. Konsep functionally gradient material (FGM) diharapkan dapat mengatasi permasalahan tersebut dengan menyesuaikan sifat mekanis pasak terhadap sifat setiap bagian gigi. Penelitian ini bertujuan mengembangkan material pasak dengan konsep FGM dari bahan $\mathrm{Ti} / 40 \mathrm{HA}$ yang tersusun atas lima layer dengan konsentrasi HA dari 0\% - 40\%wt melalui proses uni-axial pressing diikuti sintering pada $1200^{\circ} \mathrm{C}$ dan $1400^{\circ} \mathrm{C}$ dalam gas Argon. Kemudian dilakukan karakterisasi pada setiap layer dengan SEM/EDX, Suhu sintering optimum ditentukan dengan uji-t $(\mathrm{p}<0,05)$. Pengujian morfologi menunjukkan komposit Ti/40HA masih bersifat porus, sedangkan EDX menunjukkan kenaikan komposisi Ca dan P sebagai indikasi kenaikan konsentrasi HA seiring turunnya konsentrasi Ti dari layer ke-1 (100\%Ti) sampai layer ke-5 (60\%Ti-40\%HA). Sebagai kesimpulan, material komposit Ti/40HA200, dan Ti/40BHA dapat dihasilkan dengan penurunan kekerasan seiring naiknya konsentrasi HA pada setiap bagian.
\end{abstract}

Kata Kunci: functionally gradient material, Titanium, Hidroksiapatit, Hardness. 


\section{PENGANTAR}

Pasak endodontik yang beredar di pasaran saat ini, baik paduan logam, fiber maupun komposit mempunyai komposisi dan struktur yang homogen dari ujung yang satu, pada daerah koronal, sampai ujung yang lain, pada daerah apikal. Apabila suatu gaya dikenakan pada mahkota gigi seperti pada waktu pengunyahan atau trauma, momen rotasional yang ditransmisikan melalui pasak endodontik dengan struktur homogen tersebut ke dentin di sekitar apeks dari pasak sering mengakibatkan terjadinya retak dan patah pada akar gigi (Watari dkk., 2006).

Kombinasi dari serbuk Ti dan HA sebagai logam dan keramik biasa disebut dengan Functionally Graded Plate (Shahrjerdi dkk.,2011). Hidroksiapatit sebagai material biomekanis mempunyai titik leleh (melting point) yang mendekati titik leleh Titanium. Ti mempunyai kekakuan yang tinggi (high stiffness) dan mempunyai kemampuan untuk mengalami komposisi powder yang baru. Sifat tersebut dapat menurunkan diskontinuitas dari layer yang terbentuk dan meningkatkan homogenitas powder.KombinasidariTidanHA kemungkinan dapat menjadi komponen pengganti jaringan keras yang sempurna dalam tubuh manusia karena sifatnya yang secara dekat menyerupai sifat-sifat kimia dan kristalografis dari tulang dan gigi manusia (Nindhia dkk., 2008: 28-33; Herliansyah dkk., 2010).

Penelitian yang akan dilakukan ini memiliki sejumlah tujuan diantaranya adalah untuk menghasilkan paduan komposit Ti/40HA dengan struktur functionally gradient yang sesuai untuk aplikasi pembuatan pasak endodontik dengan konsep functionally graded structure material dan untuk mengetahui sifat mekanis berupa kekerasan komposit functionally gradient Ti/40HA (menggunakan HA bovine dan HA komersial).

Komposit Ti/40HA struktur functionally gradient dibuat dengan mencampurkan (2 jam) serbuk Titanium (Ti) dan Hidroksiapatit (masing-masing BHA dan HA200) dengan komposisi yang gradual: $\mathrm{Ti}, \mathrm{Ti}-10 \mathrm{HA}, \mathrm{Ti}-$
20HA, Ti-30HA, Ti-40HA, yang dinyatakan dalam \%wt $\mathrm{s}$ di bawah. Masing-masing campuran serbuk tersebut secara berurutan dimasukkan dalam lubang cetakan stainless steel berukuran $\varnothing 5 \times 20 \mathrm{~mm}$ dengan struktrur yang gradien dari mulai titanium murni pada ujung satu, sampai Ti-40HA pada ujung yang lain lalu dilakukan kompaksi menggunakan tekanan uni-aksial untuk membuat green body. Kompaksi dilakukan untuk membuat spesimengreenbodydengancara menggunakan tekanan kompaksi $450 \mathrm{MPa}$ (900 kg). Proses kompaksi dilakukan secara perlahan dengan rerata kenaikan beban sekitar $25 \mathrm{MPa}$ /menit.



Gambar 1. Green Body FGM Ti/40HA Sebelum Proses Sintering

Green body tersebut kemudian disinter (3 jam) dalam kondisi gas Argon pada $1200^{\circ}, 1300^{\circ}$ dan $1400^{\circ} \mathrm{C}$ untuk tiap-tiap kelompok sampel (4 buah sampel Ti/40BHA dan 4 buah sampel Ti/40HA200 untuk tiap kelompok) untuk menghasilkan sampel yang padat. Proses sintering merupakan proses pemadatan serbuk dengan cara membentuk ikatan batas butir antar-serbuk penyusunnya. Produk hasil proses sintering, dilakukan pengujian kekerasan (Vickers Hardness) yang dilakukan pada tiap-tiap bagian (layer) dari sampel FGM. Tiap lapisan dilakukan 3 kali penginjakan di titik yang berbeda dalam satu lapisan (layer) tersebut. Waktu indentasi yang digunakan adalah $10 \mathrm{~s}$, dengan kelajuan kontak indenter dengan material adalah $60 \mu \mathrm{m} / \mathrm{s}$. Toleransi waktu aplikasi gaya adalah \pm 2 s. Pengujian dilakukan dengan pengulangan sebanyak 4 kali untuk masing-masing kelompok sampel. Hasil kekerasan tiap layer diambil dari nilai rata-rata kekerasan Vickers pada tiap layer pada 3 sampel pengulangan. 


\section{PEMBAHASAN}

Hasil sintering adalah berupa specimen FGM Ti/40HA berwarna kuning pucat keputihan pada bagian kulit (shell). Pada bagian dalam specimen, struktur gradien terlihat dari mulai Ti murni yang berwarna keabu-abuan mengkilat (metalic grey) pada ujung satu sampai dengan struktur Ti-40HA di ujung yang lain (Gambar 2).

Spesimen pada sintering dengan suhu $1300^{\circ} \mathrm{C}$ secara umum mengalami proses penyatuan Titanium dan Hidroksiapatit yang kurang optimal. Pada sintering menggunakan suhu $1300^{\circ} \mathrm{C}$ dihasilkan sampel Ti/40HA200 yang sebagian dari layer-layernya masih bersifat rapuh terutama dibagian dalam. Begitu juga dengan sampel Ti/40BHA yang dihasilkan yang bagian dalam sampel sangat rapuh terutama pada bagian ujung sampel dengan konsentrasi BHA yang tinggi (Ti40BHA dan Ti-30BHA). Ada beberapa kemungkinan yang menyebabkan kerapuhan pada sampel Ti/40BHA tersebut.



Gambar 2. Tampang Lintang Spesimen FGM Ti/40HA Hasil Sintering

\section{Struktur Morfologi FGM Ti/40HA}

Gambar 3 dan 4 menunjukkan hasil SEM pada layer pertama (Ti murni) dan pada layer kedua (Ti-10HA200). Pada layer pertama dengan komposisi Ti murni, dapat dilihat bahwa struktu masih berupa porous. Rongga-rongga juga terlihat pada layer kedua (Ti-10HA200) yang masih dapat ditemukan pada matriks Ti (berwarna kehitaman) dan HA (berwarna keputihan).



Gambar 3. Scanning Electron Micrograph dari Layer Pertama (100\% Ti)



Gambar 4a. Scanning Electron Micrograph dari Layer Kedua $(90 \% \mathrm{Ti}+10 \% \mathrm{HA})$

Rongga-rongga ini, seperti pada layer $\mathrm{Ti}$ murni, masih terjadi dikarenakan pada akhir tahap awal sintering terjadi pertumbuhan butir, sehingga ukuran butir rata-rata menjadi lebih besar dan jumlah butir menjadi berkurang. Bersamaan dengan pengurangan jumlah butir ada kemungkinan terjadinya sifat isolasi pori-pori dan memperlambat laju sintering (German, 1994).

Scanning electron micrograph pada layer selanjutnya, yaitu layer ke-3 sampai ke-5 (Ti-20HA200, Ti-30HA200, dan Ti-40HA200) dapat dilihat pada Gambar 4-5. Gambar tersebut memperlihatkan bahwa pada layer-layer tersebut rongga-gongga juga masih terbentuk. Rongga-rongga tersebut nantinya dapat mempengaruhi sifat mekanis dari produk sintering karena akan lebih besar kemungkinannya terjadi crack yang kemudian akan menjalar dan akan menjadi kerusakan pada sesimen secara utuh. 


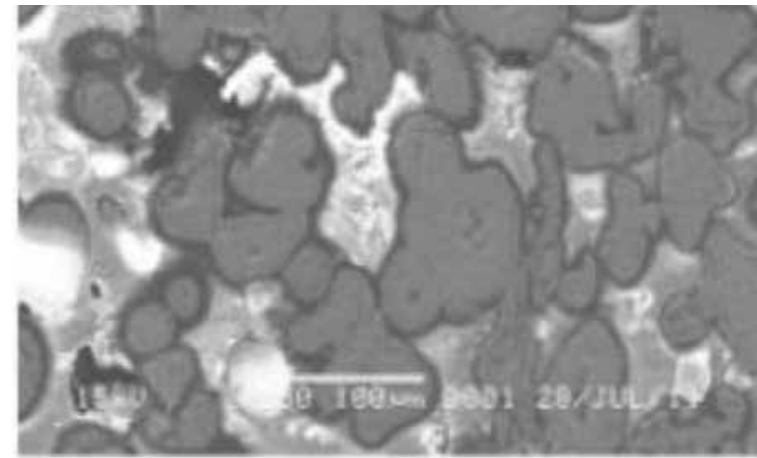

Gambar 4b. Scanning Electron Micrograph dari Layer Ketiga (80\% Ti+20\%HA)

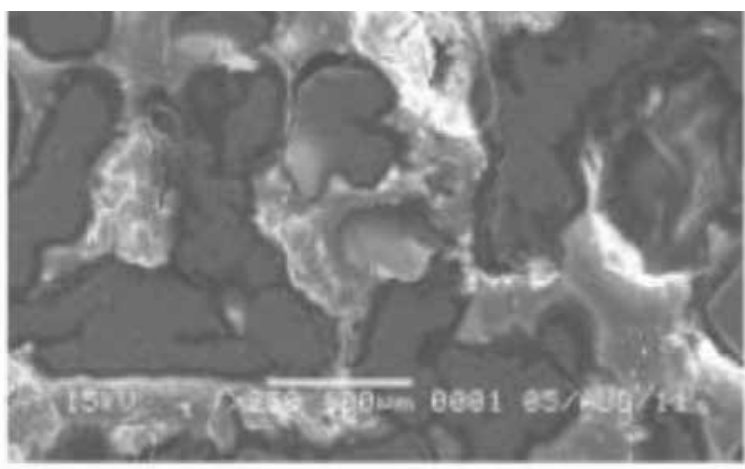

Gambar 5. Scanning Electron Micrograph dari Layer Keempat (70\% Ti+30\%HA)

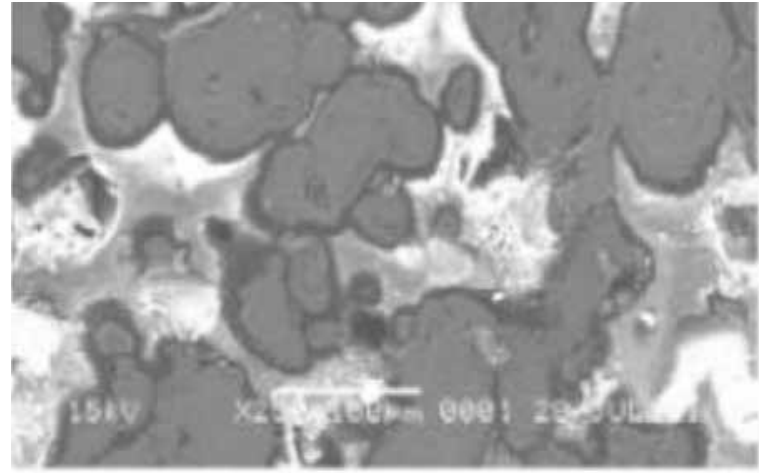

Gambar 6. Scanning Electron Micrograph dari Layer Kelima (60\% Ti+40\%HA)

\section{Uji Kekerasan}

Hasil uji kekerasan spesimen FGM Ti/40HA menggunakan metode Vickers, secara umum didapatkan nilai kekerasan tiap-tiap layer dalam sampel Ti/40HA200 maupun Ti/40BHA yang menurun mulai dari layer Ti murni sampai Ti-40HA seperti terlihat pada Tabel 1 serta Gambar 7 dan Gambar 8 (Watari dkk., 2003 dan Yokoyama dkk., 1999). Nilai kekerasan Ti sesuai dengan nilai kekerasan dari unalloyed commercial Titanium yaitu sekitar 250-500 VHN.

Tabel 1. Kekerasan Rata-Rata Tiap Layer Sampel FGM Ti/40HA

\begin{tabular}{|l|l|l|l|l|l|l|}
\hline \multirow{2}{*}{ Material } & \multicolumn{2}{|c|}{ Temperatur Sintering } & \multicolumn{5}{c|}{ Kekerasan } \\
\cline { 3 - 7 } & \multicolumn{1}{|c|}{ Layer 1 } & Layer 2 & Layer 3 & Layer 4 & Layer 5 \\
\hline \multirow{2}{*}{$\mathrm{TI} / 40 \mathrm{BHA}$} & $1200^{\circ} \mathrm{C}$ & 240.31 & 72.19 & 38.80 & 30.19 & 27.03 \\
\cline { 2 - 7 } & $1400^{\circ} \mathrm{C}$ & 242.85 & 100.77 & 27.68 & 21.79 & 18.00 \\
\hline \multirow{2}{*}{$\mathrm{TI} / 40 \mathrm{HA} 200$} & $1200^{\circ} \mathrm{C}$ & 234.84 & 35.27 & 27.06 & 27.75 & 22.27 \\
\cline { 2 - 7 } & $1400^{\circ} \mathrm{C}$ & 325.48 & 94.30 & 39.69 & 23.83 & 24.00 \\
\hline
\end{tabular}

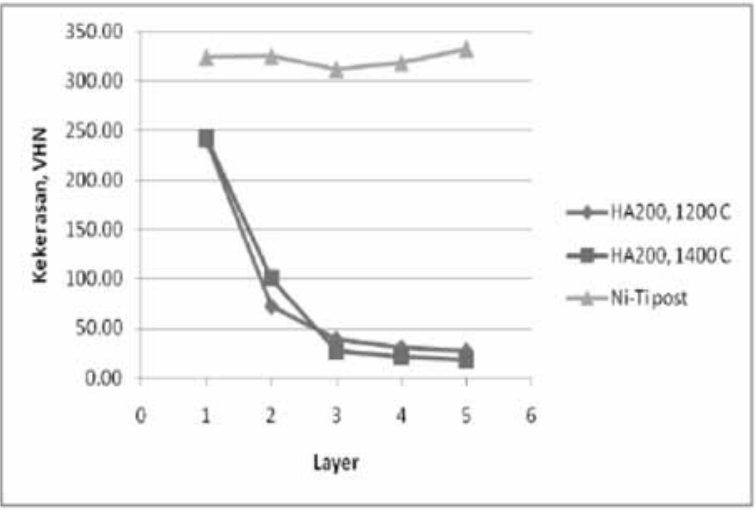

Gambar 7. Kekerasan FGM Ti/40HA200 Setelah Disintering $1200^{\circ} \mathrm{C}$ dan $1400^{\circ} \mathrm{C}$

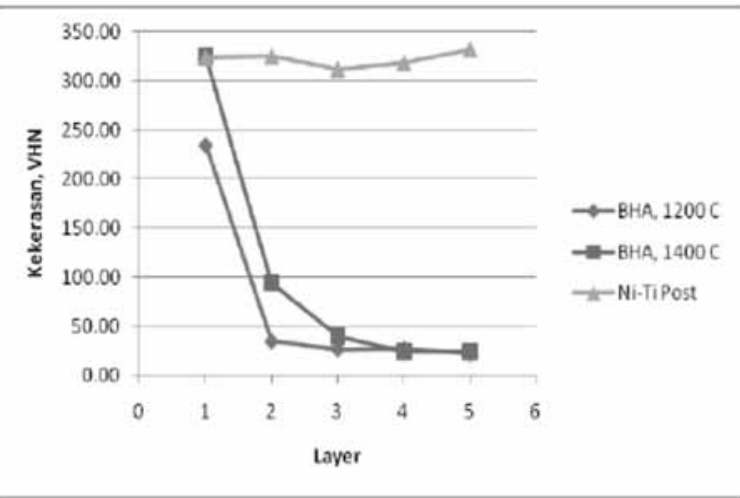

Gambar 8. Kekerasan FGM Ti/40HA200 setelah disintering $1200^{\circ} \mathrm{C}$ dan $1400^{\circ} \mathrm{C}$ 
Pengujian menggunakan t-test dilakukan untuk mencarisuhu sintering optimum untuk tiap layer pada FGM Ti/40HA200 maupun Ti/40BHA dengan cara membandingkan layer pertaman pada Ti/40HA200 yang disintering pada suhu $1200^{\circ} \mathrm{C}$ (kelompok 1) terhadap layer pertama sampel Ti/40HA200 yang disintering pada $1400^{\circ} \mathrm{C}$ (kelompok 3), layer kedua dari kelompok 1 dan layer kedua dari kelompok 3 dan seterusnya sampai layer ke lima. Pembandingan tiap layer seperti itu juga dilakukan pada sampel Ti/40BHA $1200^{\circ}$ $\mathrm{C}$ (kelompok 4) terhadap $1400^{\circ} \mathrm{C}$ (kelompok 6). Hasil uji-t bisa dilihat pada Tabel 2 dan 3 .

Tabel 2. Hasil $t$-test FGM Ti/40HA200

\begin{tabular}{ccccc}
\hline & 1200 & & 1400 & Sig*. \\
\hline \hline \multirow{2}{*}{ Layer } & 1 & vs & 1 & 0,918 \\
& 2 & vs & 2 & 0,196 \\
& 3 & vs & 3 & 0,001 \\
& 4 & vs & 4 & 0,001 \\
& 5 & vs & 5 & 0,000 \\
\hline
\end{tabular}

*signifikansi $\mathrm{p}<0,05$

Tabel 3. Hasil $t$-test FGM Ti/40BHA

\begin{tabular}{ccccc}
\hline & 1200 & & 1400 & Sig*. \\
\hline \hline Layer & 1 & vs & 1 & 0,000 \\
& 2 & vs & 2 & 0,000 \\
& 3 & vs & 3 & 0,012 \\
& 4 & vs & 4 & 0,363 \\
& 5 & vs & 5 & 0,438 \\
\hline
\end{tabular}

*signifikansi $\mathrm{p}<0,05$

Struktur akar gigi secara umum dibagi menjadi tiga bagian, yaitu bagian koronal, medial, dan apikal. Dengan melihat hasil uji statistika pada Gambar 4 dan 5 tersebut, dapat direkomendasikan bahwa pada FGM Ti/HA dalam aplikasinya ke pasak endodontik, layer ke-5 (Ti-40HA) dapat dieliminasi dari struktur FGM karena nilai kekerasannya tidak berbeda secara signifikan dengan layer ke-4. Dengan kata lain, nilai konsentrasi HA maksimal pada FGM Ti/HA hanya cukup sampai dengan $30 \%$.

\section{SIMPULAN}

Spesimen FGM Ti/40HA200 dan Ti/40BHA bisa difabrikasi dengan metode powder metallurgy yaitu dengan menggunakan uniaxial pressure dan electric furnace sintering. Pasak endodontik Ni/ Ti yang merupakan paduan logam akan memiliki sifat mekanis (kekerasan) yang lebih tinggi dari komposit Ti/40HA struktur FG, tetapi pasak endodontik dari komposit FG Ti/HA akan memiliki distribusi tegangan yang lebih optimum karena functionally graded material dengan nilai kekerasan yang menurun secara gradual dari layer pertama (Ti murni), sampai layer terakhir (Ti-40HA). Melihat dari nilai kekerasan di tiap layernya, nilai kekerasan yang relatif besar pada layer ke-1 dapat diasosiasikan dengan kekuatan yang besar yang diperlukan pada ujung atas pasak endodontik (bagian koronal) yang akan secara langsung berkontak dengan gaya luar. Menurunnya nilai kekerasan ke arah bagian akar gigi akan berkontribusi terhadap adanya stress relaxation yang akan menghindarkan bagian dentin akar gigi dari kerusakan (damage).

\section{DAFTAR PUSTAKA}

German, R. M., Powder Metallurgy Science, 1994, Princeston, New Jersey, USA.

Herliansyah, M.K., Toque, J.A., Hamdi, M., Ide-Ektessabi, A. dan Wildan, M.W., 2006, Fabrication of Bovine Bone Hydroxyapatite: effect of the material shapes and calcination temperature, ISTECS Journal, Vol.VII:25-33. 
Wildan, W., Tontowi, A. E., Suyitno, dan Dewo, P., 2010, Natural Hydroxyapatite: A Comparative Study of Bovine Hydroxyapatite, Calcite Hydroxyapatite and Gypsum Hydroxyapatit, Proceeding of the 1st International Conference on Materials Engineering (ICME) and 3rd AUN/ SEED-Net Regional Conference on Materials (RCM).

Nindhia T., Koyoshi Y, Kaneko A, Sawada H, Ohta M, dan Hirai S, 2008, Hydroxyapatite-Silk Functionally Graded Material by Pulse Electric Current Sintering, Trends Biomater. Artif. Organ., 22(1): 28-33.

Ooi, C. Y., Hamdi, M. dan Ramesh, S., 2007, Properties of Hydroxyaptite produced by annealing of Bovine Bone, Ceramics International, 33, 11711177.

Shahrjerdi, A., Mustapha, M., Bayat, M., Sapuan, S.M., dan Majid, D.L.A., 2011, Fabrication Of Functionally Graded Hydroxyapatite-Titanium By Applying Optimal Sintering Procedure And Powder Metallurgy, International Journal of the Physical Sciences, Vol. 6(9), 2258-2267.
Watari, F., Liao, S., Yokoyama, A., Omori, M., dan Ohata, N., 2006, FGM's for Biomedical Applications, Advances in Science and Technology, Vol. 45, 1124-1133.

Kondo, H., Matsuno, H., Miyao, R., Yokoyama, A., Omori, M., Hirai, T., Tamura, Y., Uo, M., Ohara, N., dan Kawasaki, T., 2003, Development of Functionally Graded Implant and Dental Post for Biomedical Application, Materials Science Forum, Vols 423-43, 321-326.

Yokoyama, A., Matsuno, H., Saso, F., Uo, M., dan Kawasaki, 1999, Biocompatibility of Titanium/ Hydroxyapatite dan Titanium Cobalt Functionally Graded Implant, Materials Science Forum, Vols. 309311, 356-361.

Yokoyama, A., Watari, F., Miyao, R., Matsuno, H., Uo, M., Kawasaki, T., Kohgo, T., Omori, M., dan Hirai, T., 2001, Mechanical Properties And Biocompatibility Of TitaniumHydroxyapatite Implant Material Prepared By Spark Plasma Sintering Method, Key Engineering Materials, Vols. 192-195, 445-44. 